Editorial

Red Beetroot Thematic Issue

\title{
Thematic Issue on "Red Beetroot as a Source of Nutrients, Bioactive Compounds and Pigments"
}

\author{
Wieslaw Wiczkowski \\ Guest Editor of Thematic Issue \\ Institute of Animal Reproduction and Food Research, Polish Academy of Sciences in Olsztyn, \\ Tuwima 10 Str., 10-748 Olsztyn, Poland
}

This Thematic Issue of Polish Journal of Food and Nutrition Sciences deals with the trans-disciplinary aspects of red beetroot as well as the red beetroot-derived products in the following topics: processing and storage - effect on the quality and functionality; bioactive constituents and nutritional value; profile, absorption, metabolism, and bioavailability of phytochemicals; potential health-promoting and microbiological activities; and new analytical methods for compounds study.

Due to the development of civilization diseases, increasing attention is paid not only to the nutritional value and sensory attractiveness of certain food-plants and their products but, above all, to their profile and content of bioactive compounds since these issues may have a positive impact on human health. The bioactive compounds of red beetroots that have been studied in the seven published articles of the Thematic Issue are of a varied nature and activity, ranging from betalains and saponins to phenolic acids and flavonoids. In this context, the report of Kumorkiewicz et al. [2020] presents for the first time the new bidecarboxylated betanins (which might have a strong bioactivities) in red beetroot extract as well as their generation from betanin/isobetanin and mono-decarboxylated betanins during the process of heating. On the other hand, the thermal stability of betalains present in by-products of red beetroot and their degradation along with raising temperature is manifested by the production of various betalain degradation products that have been determined in the work of Otálora et al. [2020]. Next, Czyżowska et al. [2020] investigated the effect of long-term cold storage of fermented beetroots and fermented beetroots juice on the content of biologically active compounds and microorganisms. In turn, Tumbas Šaponjac et al. [2020] studied the encapsulation of bioactive compounds from red beetroot juice with soybean proteins and determined the physicochemical characteristics of these encapsulates. Another interesting research article by Spórna-Kucab \& Wybraniec [2020] focused on the analysis of sa-

\footnotetext{
* Corresponding Author: E-mail: w.wiczkowski@pan.olsztyn.pl (W. Wiczkowski)
}

ponins, being natural plant compounds exhibiting health benefits, in red beetroot for the first time using high-speed counter-current chromatography in a new solvent system consisting of tert-butyl-methyl ether-butanol-acetonitrile-water. Aspects related to the fate of red beetroot phytochemicals after intake, such as the change in the total phenolics content, total flavonoids content, contents of betacyanins and, betaxanthins, phenolic acids profile as well as the antioxidant activity after simulated gastrointestinal digestion of red beetroot juice have been described by Desseva et al. [2020]. Finally, the study of Ptatosz et al. [2020] shows the profile of phenolic acids and flavonoids of red beetroot and its fermentation product and explains whether the long-term consumption of fermented red beetroot juice affects phenolic compounds profile in plasma and urine of volunteers.

All these articles are actually highlighting the great potential of red beetroot and its products along with their various natural compounds as well as show that this vegetable arouses the interest of scientists from various corners of the world. At the same time, it should be emphasized that a number of aspects regarding the transformation of red beetroot phytochemicals during technological processes and also after consumption during digestion, absorption, and metabolism processes have not yet been discovered.

I would like to thank the Authors for their important work in the field of red beetroot as a source of bioactive compounds and pigments.

\section{REFERENCES}

1. Czyżowska, A., Siemianowska, K., Śniadowska, M., Nowak, A. (2020). Bioactive compounds and microbial quality of stored fermented red beetroots and red beetroot juice. Polish Journal of Food and Nutrition Sciences, 70(1), 35-44.

2. Desseva, I., Stoyanova, M., Petkova, N., Mihaylova, D. (2020). Red beetroot juice phytochemicals bioaccessibility: an in vitro approach. Polish Journal of Food and Nutrition Sciences, 70(1), $45-53$. 
3. Kumorkiewicz, A., Sutor, K., Nemzer, B., Pietrzkowski, Z. Wybraniec, S. (2020). Thermal decarboxylation of betacyanins in red beet betalain-rich extract. Polish Journal of Food and Nutrition Sciences, 70(1), 7-14.

4. Otálora, C.M., Bonifazi, E.L., Fissore, E.N., Basanta, M.F., Gerschenson, L.N. (2020). Thermal stability of betalains in by-products of the blanching and cutting of Beta vulgaris L. var conditiva. Polish Journal of Food and Nutrition Sciences, 70(1), 15-24.

5. Płatosz, N., Sawicki, T., Wiczkowski, W. (2020). Profile of phenolic acids and flavonoids of red beet and its fermentation products. Does long-term consumption of fermented beetroot juice affect phenolics profile in human blood plasma and urine? Polish Journal of Food and Nutrition Sciences, 70(1), 55-65.

6. Spórna-Kucab, A., Wybraniec, S. (2020). High-speed countercurrent chromatography in separation and identification of saponins from Beta vulgaris L. cultivar Red Sphere. Polish Journal of Food and Nutrition Sciences, 70(1), 67-74.

7. Tumbas Šaponjac, V.T., Čanadanović-Brunet, J.M., Ćetković, G.S., Jakišić, M.V., Vulić, J.J., Stajčić, S.S., Šeregelj, V.N. (2020). Optimisation of beetroot juice encapsulation by freeze-drying. Polish Journal of Food and Nutrition Sciences, 70(1), 25-34. 